\section{Joy at last for ESA's science}

\section{Munich \& London}

After years of argument and uncertainty, the European Space Agency (ESA)'s council last week agreed to increase the agency's budget for space science in 1993 and 1994, dispelling fears that important projects would be cut because of a lack of funds. The agreement comes as a welcome surprise for European space scientists, because many national delegates, particularly the British, were reluctant to agree increases to the science budget unless convinced that ESA was enacting measures to reduce unnecessary costs (see Nature 348, 474; 6 December 1990).

The 13 member states agreed to increase spending on science by 5 per cent a year in real terms in both 1993 and 1994, reaching a target of 260 million accounting units (MAU) a year (about $£ 180$ million) at today's prices. A further $8 \mathrm{MAU}$ has been found for the Hipparcos star-mapping project in 1991. The operation of Hipparcos is costing much more than expected because the satellite has to communicate with three ground stations, rather than one, after failing to reach a geostationary orbit after launch.

The key to the new budget agreement was a resolution requiring Jean-Marie Luton, director-general of ESA, to reduce the overheads charged to the science programme for the use of ESA facilities. This should release an extra 15 MAU a year for science from 1992. Luton also has to streamline the programme's management, with the aim of saving a further 10 MAU a year. British National Space Cen- tre officials are delighted with the assurances to increase cost efficiency: they had drafted the resolution before travelling to Paris for the council meeting, but were unsure if other ESA states would support it.

The cost-cutting measures agreed were both recommendations of an independent review commission led by Klaus Pinkau of the Max Planck Institute for Plasma Physics near Munich. But member states baulked at endorsing the most politically sensitive of the Pinkau recommendations - the relaxation of the strict rule that awards equipment manufacturing contracts to ESA member states in proportion to their financial contributions. This was rejected by the less industrially developed ESA nations, which joined the agency to obtain a guaranteed supply of manufacturing contracts for their fledg-

Roger Bonnet, ESA's director of space science, says the meeting was "a tremendous success". $\mathrm{He}$ is particularly pleased with the British endorsement of the increased budget - the long-running crisis surrounding ESA's science budget was precipitated by Britain's refusal in 1987 to fall in line with the other 12 member states over budget increases.

The ESA space science programme includes both joint European-US projects such as the ESA Huygens probe to Titan on the US Cassini Saturn mission planned for 1997 and solely European missions, including the Infrared Space Observatory, due for launch in 1993.

Steven Dickman \& Peter Aldhous ling space technology industries.

\title{
All under control
}

\section{London}

BritisH ecology will celebrate the New Year with the opening on 9 January of a unique ecology research facility at the Centre for Population Biology. The new \&1-million facility, the Ecotron, will make it possible to model complete ecosystems in precisely controlled environments.

At the core of the Ecotron are 16 walk-in chambers with computer-controlled climates. These chambers will be used to establish self-sustaining communities of animals and plants, allowing researchers

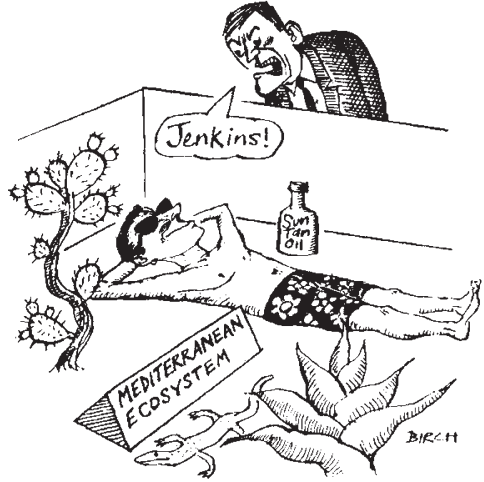

to study the assembly of ecosystems, the make-up and stability of food webs, and the ways in which populations interact at different spatial scales.

Although controlled environment chambers are widely used in ecological research to study specific interactions, the Ecotron is the first facility to allow researchers to control model ecosystems precisely. In the longer term, scientists want to use the Ecotron to study the ecological effects of global warming or climate change and pollution, and possibly also the interplay between genetics and population dynamics.

The Ecotron is the centrepiece of the Centre for Population Biology at Silwood Park, near Ascot. The centre, which is part of Imperial College, was set up in April 1989.

Rory Howlett

\section{London}

THE first-ever British astronaut will fly to the Soviet Mir space station in May 1991, now that a package has been put together to rescue the Juno mission, which collapsed during the summer after failing to attract commercial sponsorship (see Nature 346, 781; 30 August 1990). But the future for the programme of microgravity experiments which was to have accompanied the astronaut is still in question.

The mission's original financial backer, the London-based Moscow Narodny Bank, is paying an undisclosed sum of money to NPO Energiya, which builds launch vehicles for the Soviet space programme, to ensure a flight for one of the two British astronauts still in training near Moscow. Tim Mace, a major in the Army Air Corps, and Helen Sharman, a food technologist, must wait until next month before the final astronaut selection is made.
The bank says that Juno will have a science programme, but this may now consist of Soviet rather than British experiments. Heinz Wolff, from Brunel University, science director for the original mission, says he needs $£ 250,000$ to run eight of the 18 experiments that were scheduled to fly. But Wolff is having difficulty attracting sponsors, because the bank has provided little information on the exposure that sponsors will receive.

Wolff says that it is important that Juno should be seen as a "serious British scientific mission", after the "negative publicity" attracted by the recent flight to Mir by a Japanese astronaut. Toyohiro Akiyama, a journalist with the Tokyo Broadcasting System television company, spent much of his time in space informing the Japanese public about his space sickness and Mir's poor toilet facilities (see Nature 348, 575; 13 December 1990).

Peter Aldhous

\section{EDUCATION}

\section{Reading the stars}

New Delhi

INDIA's Department of Space (DOS) has drawn up an ambitious plan to use space technology to tackle the country's illiteracy problem. It aims to launch a pair of satellites dedicated to beaming classroom education to every rural household. The programme, known as Gramsat (gram is Hindi for village), is aimed primarily at the inhabitants of India's 560,000 villages, 70 per cent of whom are illiterate. Gramsat will be unique in providing education in the mother tongue.

The two Gramsat satellites will cost $\$ 150$ million, according to Dr U. R. Rao, who heads DOS. He expects the first satellite to be launched in 1995. Formal government approval is awaited.

K. S. Jayaraman 